\title{
Resistance of Aegilops longissima to the Rusts of Wheat
}

\author{
Shuyi Huang and Brian J. Steffenson, ${ }^{\dagger}$ Department of Plant Pathology, University of Minnesota, St. Paul, 55108; Hanan Sela, Institute for \\ Cereal Crops Improvement, Tel Aviv University, Tel Aviv 6139001, Israel; and Kathryn Stinebaugh, School of Public Health, University of \\ Minnesota, Minneapolis, 55455
}

\begin{abstract}
Stem rust (caused by Puccinia graminis f. sp. tritici), leaf rust (P. triticina), and stripe rust ( $P$. striiformis f. sp. tritici) rank among the most important diseases of wheat worldwide. The development of resistant cultivars is the preferred method of controlling rust diseases because it is environmentally benign and also cost effective. However, new virulence types often arise in pathogen populations, rendering such cultivars vulnerable to losses. The identification of new sources of resistance is key to providing longlasting disease control against the rapidly evolving rust pathogens. Thus, the objective of this research was to evaluate the wild wheat relative Aegilops longissima for resistance to stem rust, leaf rust, and stripe rust at the seedling stage in the greenhouse. A diverse collection of 394 accessions of the species, mostly from Israel, was assembled for the study, but the total number included in any one rust evaluation ranged from 308 to 379 . With respect to stem rust resistance, 18.2 and $80.8 \%$ of accessions were resistant to the widely virulent U.S. and Kenyan $P$. graminis f. sp. tritici races of TTTTF and TTKSK, respectively. The percentage of accessions exhibiting

resistance to the U.S. P. triticina races of THBJ and BBBD was 65.9 and $52.2 \%$, respectively. Over half $(50.1 \%)$ of the Ae. longissima accessions were resistant to the U.S. P. striiformis f. sp. tritici race PSTv-37. Ten accessions (AEG-683-23, AEG-725-15, AEG-803-49, AEG-1274-20, AEG1276-22, AEG-1471-15, AEG-1475-19, AEG-2974-0, AEG-4005-20, and AEG-8705-10) were resistant to all races of the three rust pathogens used in this study. Distinct differences in the geographic distribution of resistance and susceptibility were found in Ae. longissima accessions from Israel in response to some rust races. To $P$. graminis $\mathrm{f}$. sp. tritici race TTKSK, populations with a very high frequency of resistance were concentrated in the central and northern part of Israel, whereas populations with a comparatively higher frequency of susceptibility were concentrated in the southern part of the country. The reverse trend was observed with respect to $P$. striiformis f. sp. tritici race PSTv-37. The results from this study demonstrate that Ae. longissima is a rich source of rust resistance genes for wheat improvement.
\end{abstract}

Bread wheat (Triticum aestivum L.) is one of the most important food crops in the world, supplying nearly one third of the calories consumed by humans. Unfortunately, the crop is vulnerable to many diseases, due in part to the narrowing of genetic diversity through polyploidization, domestication, and years of intensive breeding. Of the major biotic threats to wheat production, the rust diseases rank among the most widely distributed and devastating. These rust diseases include: stem rust caused by Puccinia graminis Pers.:Pers. f. sp. tritici Eriks. \& E. Henn., leaf rust caused by P. triticina Eriks., and stripe rust caused by $P$. striiformis Westend. f. sp. tritici Eriks. (Roelfs et al. 1992). In many wheat growing regions of the world, these rust diseases continue to be an important production constraint (Vikas et al. 2014). The average annual losses on a global scale are estimated at 6.20 million $t$ (value of US $\$ 1.12$ billion) for stem rust, 5.76 million t (US $\$ 1.03$ billion) for leaf rust, and 5.47 million $t$ (US $\$ 979$ million) for stripe rust (Beddow et al. 2015; Pardey et al. 2013; Y. Chai, personal communication).

Stem rust has historically been the most damaging rust disease of wheat in many parts of the world (Roelfs and Bushnell 1985). It is capable of completely destroying crops during severe epidemics, but yield losses ranging from 50 to $70 \%$ are more common (Roelfs et al. 1992). In the northern Great Plains of North America, deployment of resistant cultivars is the primary means of control. Early efforts

${ }^{\dagger}$ Corresponding author: B. J. Steffenson; E-mail: bsteffen@umn.edu

Funding: This research was supported in part by the Lieberman-Okinow Endowment at the University of Minnesota and through a grant from the Bill \& Melinda Gates Foundation and the UK Department for International Development to Cornell University for the Borlaug Global Rust Initiative (BGRI) Durable Rust Resistance in Wheat (DRRW) Project.

*The $\boldsymbol{e}$-Xtra logo stands for "electronic extra" and indicates that four supplementary tables and seven supplementary figures are published online.

Accepted for publication 20 December 2017.

() 2018 The American Phytopathological Society at breeding stem rust-resistant wheat cultivars were met with failure when virulent races of the pathogen emerged, causing spectacular epidemics in the mid-1930s and again in the mid-1950s (Ellis et al. 2014). Since these "boom and bust" cycles, stable stem rust resistance has been achieved in wheat cultivars for more than five decades (Singh et al. 2011). This success is attributed to the incorporation of multiple effective genes in cultivars, eradication of the pathogen's alternate host (Berberis species), and diligent monitoring of new virulence types in the pathogen population (McIntosh et al. 1995).

Unfortunately, there is a new stem rust threat in the form of widely virulent $P$. graminis $\mathrm{f}$. sp. tritici races from Africa. The first described race of this unique virulence group was TTKSK (isolate synonym Ug99), discovered in Uganda in 1998 (Pretorius et al. 2000). Race TTKSK is a threat to food security because it is virulent on over $80 \%$ of the world's wheat cultivars, including those carrying the widely deployed resistance gene $S r 31$ (Singh et al. 2011). The wide virulence of TTKSK for most of the deployed resistance genes in wheat is a great concern to breeders and pathologists, as is the potential for new virulence types to emerge within the Ug99 race group. Indeed, more than a dozen variants are now recognized in the Ug99 race group (Patpour et al. 2016; Singh et al. 2015). This degree of pathogen variation makes breeding for stable stem rust resistance more complicated and difficult.

More than 60 different genes for stem rust resistance have been described in wheat and its wild relatives (BGRI 2017; McIntosh et al. 1995). Most of them are classified as race-specific genes and confer a hypersensitive reaction in the host. Although a number of new genes have been described for resistance against TTKSK and its variants (Njau et al. 2010; Singh et al. 2006; Visser et al. 2011; Wanyera et al. 2006; Yu et al. 2014), they will have to be strategically deployed in combination to attain the long-lasting resistance achieved in the past.

Leaf rust is the most common rust disease of wheat worldwide, causing more frequent epidemics than either stem or stripe rust (Bolton et al. 2008). The disease frequently causes yield losses ranging from 5 to $20 \%$, but in severe epidemics, losses up to $50 \%$ can occur (USDAARS 2016). In the United States, $P$. triticina is variable with respect to its virulence on wheat, even without a functioning sexual cycle on the 
alternative hosts of Thalictrum speciosissimum (meadow rue) and Isopyrum fumaroides (a false rue anemone). Over 70 races of $P$. triticina are detected each year in surveys throughout the country (Kolmer et al. 2007). As with stem rust, the best means of controlling leaf rust is through the use of resistant cultivars. To date, over 75 leaf rust resistance genes have been described from bread wheat, durum wheat, and diploid wild wheat relatives (Bolton et al. 2008; USDA-ARS 2015).

Over the past two decades, stripe rust has increased in importance on wheat in the United States. The most stripe rust prone area of the country is the Pacific Northwest, where losses of 5 to $40 \%$ are common. In the large wheat production area of the southern and central Great Plains region, the disease was seldom reported (Chen 2007). This situation changed in the early 2000s when stripe rust became more frequent and started causing losses in Texas, Louisiana, Arkansas, and 28 other states (Wan and Chen 2014). These epidemics were due to a new strain of $P$. striiformis $\mathrm{f}$. sp. tritici with additional virulence, increased aggressiveness, and a wider adaptation to warmer temperatures (Markell and Milus 2008; Milus et al. 2015). Since the emergence of this strain, estimated yield losses of 1.1 to 2.6 million t occurred from 2001 to 2005 in the United States with a significant portion being from the Great Plains production area (Wan and Chen 2014). The stripe rust pathogen is also variable with respect to virulence as more than 80 races have been identified in the United States since 2000 (Wan and Chen 2014).

More than 70 stripe rust resistance genes have been described or provisionally described in wheat, the majority of which confer race-specific resistance ( $\mathrm{Li}$ et al. 2011). Unfortunately, virulence for almost all of the race-specific resistance genes is known in P. striiformis f. sp. tritici. Currently, only $\mathrm{Yr} 5$ and $\mathrm{Yr} 15$ are effective against all races identified in the United States (Li et al. 2011).

The development of disease-resistant cultivars is the preferred method of controlling rust diseases because it is environmentally benign, cost-effective, and also sustainable, if the resistance genes can be strategically combined (Dakouri et al. 2013). Efficient utilization of genetic resistance relies on a complete understanding of the rust resistance genes, their durability, and effectiveness in different environments (Dakouri et al. 2013). Therefore, the identification of new sources of resistance is key to providing long-lasting disease control against the evolving rust pathogen populations (Vikas et al. 2014). Genetic diversity for disease resistance in wheat can be augmented by exploiting the primary, secondary, and tertiary gene pools. The reservoir of rust resistance genes in the primary gene pool has been extensively mined and utilized; thus, the secondary gene pool offers a potentially rich source of untapped resistance genes for wheat (Vikas et al. 2014).

The secondary gene pool includes members of the genus Aegilops (except for Ae. tauschii) that may be hybridized with cultivated wheat, but their chromosomes do not regularly pair and recombine with those of wheat unless pairing is induced artificially (Harlan and de Wet 1971). This gene pool includes the diploid Aegilops species of the section Sitopsis (Feuillet et al. 2007; Friebe et al. 1996; Mclntosh 1991), comprising the five species of Ae. bicornis (Forssk.) Jaub. \& Spach (Spach goatgrass), Ae. longissima (proposed common name: elongated goatgrass), Ae. searsii Feldman \& Kislev ex. Hammer (Sears' goatgrass), Ae. sharonensis Eig (Sharon goatgrass), and Ae. speltoides Tausch (truncate goatgrass). These five species carry the $\mathrm{S}$ genome or a modified S genome, which is closely related to the B genome of wheat (Kilian et al. 2007; van Slageren 1994). Species in section Sitopsis comprise a valuable reservoir of genetic diversity for many agronomic traits and disease resistance (Millet 2007). Indeed, a number of important resistance genes from the Sitopsis species have been transferred into cultivated wheat, including the stem rust resistance genes $\mathrm{Sr} 32, \mathrm{Sr} 39, \mathrm{Sr} 47$ (all from Ae. speltoides), and $\operatorname{Sr} 51$ (Ae. searsii); the leaf rust resistance genes $\operatorname{Lr} 28, \operatorname{Lr} 35$, Lr36, Lr47, Lr51 (all from Ae. speltoides), and Lr56 (Ae. sharonensis); the stripe rust resistance gene $\operatorname{Yr} 38$ (Ae. sharonensis); and the powdery mildew resistance genes Pm12, Pm32 (both from Ae. speltoides), and Pm13 (Ae. longissima) (Klindworth et al. 2012; Liu et al. 2011; Millet 2007; Schneider et al. 2008).
Ae. longissima is a diploid, annual grass species that is native to the eastern Mediterranean Basin. It is found across the north-south axis of western and interior Israel; in lower, coastal, and Sinai Egypt; the southern coastal plain of Lebanon; northwestern Jordan; and southern Syria (Huang 2016; van Slageren 1994). Among the five Sitopsis species, Ae. longissima possesses resistance to many diseases, but has not been fully exploited for enhancing the resistance of wheat. For example, accessions of Ae. longissima are reported to carry resistance to stem rust (Anikster et al. 2005; Scott et al. 2014), leaf rust (Anikster et al. 2005), stripe rust (Anikster et al. 2005), powdery mildew (Ceoloni et al. 1992), Septoria glume blotch (Ecker et al. 1990), and eyespot (Sheng and Murray 2013; Sheng et al. 2012, 2014). The resistances described in Ae. longissima are of little practical use in breeding unless the underlying genes can be transferred into adapted wheat germplasm. In this regard, only the dominant powdery mildew resistance gene Pml3 has been successfully transferred into wheat (Cenci et al. 1999; Ceoloni et al. 1992; Donini et al. 1995). Ae. longissima holds great potential as a valuable source of resistance to the three rust diseases of wheat. Thus, the objective of this study was to evaluate a diverse collection of $A e$. longissima germplasm for resistance to stem rust, leaf rust, and stripe rust at the seedling stage.

\section{Materials and Methods}

Plant materials. A subset of the Ae. longissima Diversity Collection (ALDIVCO; $n=433$ ) (Huang 2016) was used for the rust evaluations in this study. This subset included 394 accessions in total: 385 from Israel, four from Jordan, and five from unknown sites (Table 1, Fig. 1). Accessions from other countries (Egypt, Lebanon, and Syria) where the species is reported (Kimber and Feldman 1987; Millet 2007; van Slageren; 1994; Whitcombe 1983) were not available for study. Israel encompasses the largest and most diverse populations of Ae. longissima across its entire habitat range. Of the 385 accessions from Israel, 369 were collected from 71 ecogeographically diverse populations within the country where no more than 15 accessions were included from a single site. Sixteen additional accessions were from unknown sites in the country (Table 1, Fig. 1). The four accessions from Jordan were collected near the Dead Sea (1), Jordan River (1), and unknown sites (2). Five other Ae. longissima accessions of unknown provenance were also included in the collection. Most (372 of 394) of the Ae. longissima accessions were donated by the Harold and Adele Lieberman Germplasm Bank in the Institute for Cereal Crops Improvement (ICCI) at Tel Aviv University (Tel Aviv, Israel), with the remaining ones donated by the Leibniz-Institut für Pflanzengenetik und Kulturpflanzenforschung (IPK) in Gatersleben, Germany. Passport data were available for all of the Israeli accessions provided by the ICCI, but not those from IPK (Supplementary Table S1).

To increase homozygosity of the accessions and generate sufficient seed stocks for phenotyping, most of the Ae. longissima accessions were self-pollinated for one to four generations. The first one or two generation increases for most accessions from the ICCI were made within a net-house where spikes were not bagged. Subsequent increases of the germplasm were made inside a greenhouse at the University of Minnesota Plant Growth Facility in St. Paul. For each of these later increase generations, the spikes were bagged to prevent cross-pollination and then a single seed was advanced. Although every effort was made to increase the entire germplasm panel, some problems (e.g., poor plant growth, abnormal morphology, failure to flower, partial sterility, etc.) were encountered during cultivation, resulting in low seed stocks for several accessions. Thus, the total number of accessions included in any one rust evaluation ranged from 308 to 379 accessions.

Susceptible controls were included in each experiment to monitor the infection level (density of uredinia on leaves) and virulence (maximum uredinial size) of the pathogen races. Wheat cultivars McNair 701 (Cltr 15288), Thatcher (Cltr 10003), and Morocco (PI 431591) were the susceptible controls for the stem rust, leaf rust, and stripe rust evaluations, respectively. Additionally, the respective wheat differential lines were included in the experiments to confirm the 
identity and purity of races of $P$. graminis $\mathrm{f}$. sp. tritici, $P$. triticina, and $P$. striiformis $\mathrm{f}$. sp. tritici (Jin et al. 2008; Long and Kolmer 1989; Roelfs and Martens 1988; Wan and Chen 2014). Resistant lines within the respective differential wheat sets served as the resistant controls.

Plant growth conditions. Since Ae. longissima is a wild species, its seeds can carry undesirable dormancy. To break this dormancy and achieve uniform germination and emergence, five seeds of each accession were first germinated on filter paper moistened with distilled water in $9-\mathrm{cm}$ Petri dishes and incubated at $4^{\circ} \mathrm{C}$ for 5 days and then at room temperature $\left(22\right.$ to $\left.25^{\circ} \mathrm{C}\right)$ for 1 day. After this treatment, three seeds of each accession were planted in plastic cones $(3.8 \mathrm{~cm}$ diameter $\times 21 \mathrm{~cm}$ depth) or peat pots $(7 \times 7 \times 9 \mathrm{~cm}, 1 \times \mathrm{w} \times \mathrm{h})$ containing a 50:50 mixture of steam-sterilized native soil and plant growth medium (Sunshine MVP mix; Sungro Horticulture Distributors Inc., Agawam, MA). For convenience in handling, the cones and peat pots were set into trays holding 98 and 16 units, respectively. Plants were sown in cones and slated for evaluation with stem rust race TTTTF; both leaf rust races and the stripe rust race were grown in a greenhouse on the St. Paul campus at the University of Minnesota. Plants sown in peat pots were grown in the Minnesota Agricultural Experiment Station/Minnesota Department of Agriculture Plant Growth Biosafety Level-3 (BSL-3) Containment Facility on the St.

Table 1. Collection sites, corresponding longitude and latitude coordinates and number of Aegilops longissima accessions used in this study

\begin{tabular}{|c|c|c|c|}
\hline Collection site & Longitude & Latitude & $\begin{array}{l}\text { Number of } \\
\text { accessions }\end{array}$ \\
\hline Akko & 35.08450 & 32.92989 & 10 \\
\hline Ashalim & 34.67443 & 30.95645 & 11 \\
\hline Ashdod & 34.70007 & 31.83610 & 4 \\
\hline Be'er Sheva & 34.79576 & 31.25067 & 8 \\
\hline Be'er Sheva-Arad & 31.26642 & 34.97110 & 1 \\
\hline Beit Lid & 34.92786 & 32.33349 & 6 \\
\hline Ben Zakkay & 34.72830 & 31.85664 & 8 \\
\hline Benaya & 34.75259 & 31.84373 & 10 \\
\hline Berekhya & 34.64611 & 31.66749 & 1 \\
\hline Dimona & 35.02579 & 31.06940 & 3 \\
\hline Dorot & 34.64667 & 31.50744 & 4 \\
\hline En Gev & 35.64119 & 32.78367 & 5 \\
\hline Ge'alya Kubeiba & 34.76632 & 31.88609 & 9 \\
\hline Gevar'am & 34.61328 & 31.59199 & 9 \\
\hline Gilat & 34.66168 & 31.33539 & 11 \\
\hline Giv'at Arnon & 34.67285 & 31.66040 & 4 \\
\hline Giv'at Brenner & 34.80263 & 31.86713 & 8 \\
\hline HaBesor & 34.50523 & 31.23739 & 1 \\
\hline Hadera & 34.92245 & 32.44402 & 11 \\
\hline HaNegev Junction & 34.83688 & 31.06699 & 6 \\
\hline Hevron & - & - & 1 \\
\hline Horbat Allon & 34.96300 & 32.45040 & 3 \\
\hline Ilanot & 34.89945 & 32.28830 & 1 \\
\hline Kefar Menahem & 34.83516 & 31.73211 & 11 \\
\hline Kefar Mordechay & 34.75688 & 31.83148 & 3 \\
\hline Kefar Yona & 34.93412 & 32.31760 & 11 \\
\hline Liman & 35.11188 & 33.05918 & 5 \\
\hline Mamshit & 35.06349 & 31.02720 & 10 \\
\hline Mash'abbe Sade & 34.75162 & 31.03082 & 6 \\
\hline Mash'abbe Sade-Retamim & 34.70427 & 31.04970 & 1 \\
\hline Meffalsim & 34.56179 & 31.50268 & 1 \\
\hline Megdar Farm & 34.64875 & 31.35340 & 1 \\
\hline Nahal Hatzatz & 34.84066 & 30.89407 & 2 \\
\hline Nahal Liman & 35.10566 & 33.05052 & 11 \\
\hline Nahal Oz & 34.49776 & 31.47274 & 1 \\
\hline Nahal Solelim-Beersheba & 34.74890 & 31.26755 & 7 \\
\hline
\end{tabular}

${ }^{a}$ Collection sites of accessions are from Jordan.

$\mathrm{b}$ The specific collection sites in Israel are not known.

${ }^{\mathrm{c}}$ The specific collection sites in Jordan are not known.

$\mathrm{d}$ The country of origin is not known for five accessions.
Paul campus and evaluated with $P$. graminis f. sp. tritici race TTKSK from Kenya. The greenhouse was maintained at a day/night temperature of $25 / 17^{\circ} \mathrm{C}$ with supplemental lighting provided by $400 \mathrm{~W}$ high pressure sodium lamps, emitting between 300 and $400 \mu$ mol photons $\mathrm{s}^{-1} \mathrm{~m}^{-2}$ for $16 \mathrm{~h} /$ day. In the BSL-3 greenhouse, a day/night temperature of $22 / 19^{\circ} \mathrm{C}$ was maintained with a $14-\mathrm{h}$ photoperiod provided by $400 \mathrm{~W}$ high pressure sodium lamps emitting a minimum of $300 \mu \mathrm{mol}$ photons $\mathrm{s}^{-1} \mathrm{~m}^{-2}$.

Four fertilization treatments were applied to plants during the course of the rust phenotyping experiments: two at planting $(0.3 \mathrm{~g} / \mathrm{pot}$ of slow-release Osmocote 14-14-14 and approximately $40 \mathrm{~g} / \mathrm{liter}$ at 1/16 dilution of Peter's Dark Weather 15-0-15; Scott's Company, Marysville, $\mathrm{OH}$ ) and two additional applications (approximately 40 g/liter at 1/16 dilution of Peter's 20-10-20; Scott's Company) at weekly intervals until the plants were scored.

Pathogen isolates. Two races of $P$. graminis f. sp. tritici were used in the evaluation of the Ae. longissima panel (Table 2). Race TTTTF (isolate $02 \mathrm{MN} 84 \mathrm{~A}-1-2$ ) was selected because it is the most widely virulent race reported in the United States, producing high infection types (ITs) on all but $\mathrm{Sr} 24$ and $\mathrm{Sr} 31$ in the 20 line wheat stem rust differential set (Jin et al. 2008; Roelfs and Martens 1988). Isolate 04KEN156/04 of race TTKSK was also included in the experiment because it possesses the same virulence spectrum as the original

Table 1. (Continued)

\begin{tabular}{|c|c|c|c|}
\hline Collection site & Longitude & Latitude & $\begin{array}{l}\text { Number of } \\
\text { accessions }\end{array}$ \\
\hline Nahal Zin & 35.03710 & 30.83100 & 1 \\
\hline Nahariyya-Rosh HaNikra & 33.01839 & 35.10486 & 1 \\
\hline Nir'am & 34.58058 & 31.51892 & 8 \\
\hline Nizzanim & 34.63440 & 31.71838 & 8 \\
\hline Or-Haner & 34.60823 & 31.55348 & 2 \\
\hline Pardes Hanna & 34.93411 & 32.48272 & 2 \\
\hline Petah Tiqwa & 34.88880 & 32.08345 & 5 \\
\hline Qiryat Ono & 34.85893 & 32.05537 & 15 \\
\hline Qiryat Ono-Petah Tiqwa & 34.87340 & 32.07012 & 4 \\
\hline Raffiah Yam & 34.24458 & 31.32220 & 1 \\
\hline Ramat Aviv & 34.80549 & 32.11208 & 4 \\
\hline Rehovot & 34.81087 & 31.89447 & 10 \\
\hline Re'im & 34.45913 & 31.38640 & 8 \\
\hline Revivim & 34.81523 & 31.05056 & 1 \\
\hline Rishon LeZiyyon & 34.81121 & 31.96003 & 2 \\
\hline Ruhama-badlands & 34.71153 & 31.49777 & 2 \\
\hline Sede Boqer & 34.79345 & 30.87372 & 14 \\
\hline Shedema & 34.74031 & 31.83360 & 15 \\
\hline Shedema-Benaya & 34.74003 & 31.83927 & 9 \\
\hline Shefayyim & 34.82245 & 32.21665 & 4 \\
\hline Shemuel Hospital & 34.82426 & 31.93166 & 1 \\
\hline Shirat HaYam & 34.27177 & 31.36698 & 1 \\
\hline Shivta-Haluza & 31.01853 & 34.62270 & 1 \\
\hline Shomerat & 35.09515 & 32.95197 & 4 \\
\hline Tel Katifa & 34.30480 & 31.36420 & 1 \\
\hline Tel Mond & 34.91816 & 32.25665 & 7 \\
\hline Telalim & 34.77135 & 30.99031 & 10 \\
\hline Tel-Nof & 34.78353 & 31.83983 & 1 \\
\hline Tifrah & 34.68758 & 31.31092 & 6 \\
\hline Tifrah2 & 34.68670 & 31.31678 & 4 \\
\hline Yad Mordekhay & 34.55750 & 31.58702 & 1 \\
\hline Yaqum & 34.84211 & 32.24932 & 1 \\
\hline Yaziz-Gibton & 34.86490 & 31.85339 & 2 \\
\hline Yeroham & 34.87481 & 31.03196 & 7 \\
\hline Yeroham-Be'er Sheva & 34.87800 & 31.02850 & 1 \\
\hline Dead Sea $^{\mathrm{a}}$ & - & - & 1 \\
\hline Jordan River ${ }^{\mathrm{a}}$ & - & - & 1 \\
\hline Unknown site within Israel ${ }^{\mathrm{b}}$ & - & - & 16 \\
\hline Unknown site within Jordan ${ }^{\mathrm{c}}$ & - & - & 2 \\
\hline Unknown site ${ }^{\mathrm{d}}$ & - & - & 5 \\
\hline Total & & & 394 \\
\hline
\end{tabular}




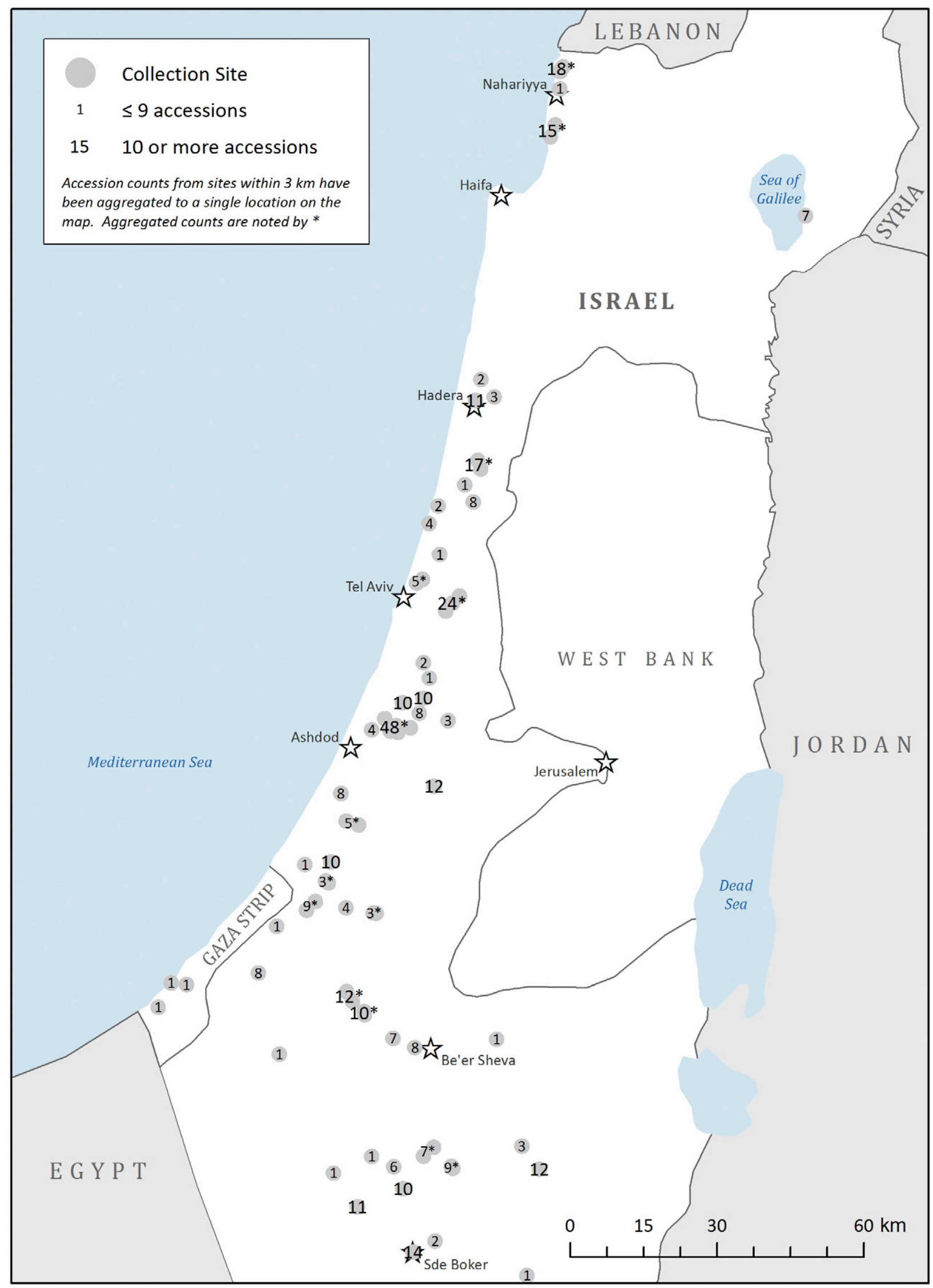

Fig. 1. Map of Israel showing the geographic distribution of Aegilops longissima accessions collected and used in this study. Twenty-two accessions donated by the Leibniz-Institut für Pflanzengenetik und Kulturpflanzenforschung (IPK) are not included in the map but were evaluated in the study. Collection sites with nine or fewer accessions are denoted with a smaller numeral and those with 10 or more accessions are denoted with a larger numeral. 
P. graminis f. sp. tritici isolate Ug99 first found in Uganda (Jin et al. 2008; Njau et al. 2010). Use of races TTTTF and TTKSK facilitated the identification of resistance that is effective against widely virulent domestic and foreign stem rust races.

Two races of $P$. triticina were used to assess the reaction of the $A e$. longissima panel to leaf rust (Table 2). Race BBBD (isolate JAK) has the narrowest virulence spectrum of races held in the USDA-ARS Cereal Disease Laboratory collection and therefore has the potential to detect the presence of many resistance genes in Ae. longissima. In contrast, race THBJ (isolate 99ND588DLL) has a much wider virulence spectrum than BBBD and is one of the most common races found in the Great Plains region of the United States. The contrasting virulence spectra of these races will facilitate the identification of different resistances in the Ae. longissima germplasm.

Race PSTv-37 of $P$. striiformis f. sp. tritici was selected for the stripe rust evaluation because it is the most predominant virulence type found in the United States (Table 2). It possesses virulence on 10 of the 18 lines in the stripe rust differential set (Wan and Chen 2014) and will identify Ae. longissima accessions with effective resistance against the most common $P$. striiformis f. sp. tritici race in the country.

The virulence phenotypes of races of all three rust pathogens were verified on the respective differential sets (Jin et al. 2008; Long and Kolmer 1989; Roelfs and Martens 1988; Wan and Chen 2014) and then increased in isolation to produce sufficient inoculum for all experiments. Races of $P$. graminis f. sp. tritici were increased on the susceptible cultivar McNair 701, those of $P$. triticina on Thatcher, and the one of $P$. striiformis f. sp. tritici on Morocco. Mass collections of urediniospores from the susceptible hosts were made using a specialized cyclone collector (Roelfs et al. 1992) attached to a small shop vacuum. After collection, urediniospores of the respective rusts were desiccated inside a $20 \%$ relative humidity chamber for 7 days at 21 to $23^{\circ} \mathrm{C}$ (stem and leaf rust) or at $4^{\circ} \mathrm{C}$ (stripe rust). Desiccated urediniospores were then placed in size 00 gelatin capsules (Gallipot, Inc., St. Paul, MN) set inside cryovials (Corning Inc., Corning, NY) and stored at $-80^{\circ} \mathrm{C}$ in a freezer until needed.

Inoculation protocol and infection/incubation period. Rust inoculations were made according to the standard protocols used at the USDA-ARS Cereal Disease Laboratory and the University of Minnesota. On the day before inoculation, urediniospores of the rust pathogens were removed from the $-80^{\circ} \mathrm{C}$ freezer, heat-shocked in a $45^{\circ} \mathrm{C}$ water bath for $15 \mathrm{~min}$, and then rehydrated in an $80 \%$ relative humidity chamber overnight. After assessing the germination rate (Scott et al. 2014), $10 \mathrm{mg}$ of urediniospores were placed into individual gelatin capsules (size 00) to which $700 \mu l$ of the oil carrier was added. The inoculum suspension was applied to 12-day-old plants (second leaf fully expanded) using custom atomizers (Tallgrass Solutions, Inc., Manhattan, KS) pressured by a pump set at 25 to $30 \mathrm{kPa}$. Approximately $0.15 \mathrm{mg}$ of urediniospores were applied per plant. Immediately after inoculation, the plants were placed in front of a small electric fan for 3 to $5 \mathrm{~min}$ to hasten evaporation of the oil carrier from leaf surfaces.
Plants were allowed to off-gas for an additional 90 min before placing them inside mist chambers. Inside the mist chambers, ultrasonic humidifiers (Vick's model V5100NSJUV; Proctor \& Gamble Co., Cincinnati, $\mathrm{OH}$ ) were run continuously for $30 \mathrm{~min}$ to provide sufficient initial moisture on the plants for the germination of urediniospores. For the next 16 to $20 \mathrm{~h}$, plants were kept in the dark and the humidifiers run for 2 min every 15 min to maintain moisture on the plants. For experiments with the stem rust pathogen, light (400W high pressure sodium lamps emitting $300 \mu \mathrm{mol}$ photon $\mathrm{s}^{-1} \mathrm{~m}^{-2}$ ) was provided for 2 to $4 \mathrm{~h}$ after the dark period to induce the final stages of the infection process, i.e., formation of penetration pegs. Then, the chamber doors were opened halfway to allow the leaf surfaces to dry completely before returning the plants to the greenhouse under the same conditions described above.

The inoculation/incubation protocols used for leaf rust were the same as described for stem rust with two modifications: (i) the concentration of inoculum applied to plants was approximately $0.033 \mathrm{mg}$ urediniospores per plant, and (ii) no light was provided during the final stages of infection by $P$. triticina. Protocols for the stripe rust experiments were the same as described for leaf rust, except that for the infection period, plants were placed inside a dew chamber at $10^{\circ} \mathrm{C}$ and $100 \% \mathrm{RH}$ for $24 \mathrm{~h}$. Thereafter, for the incubation period, plants were moved into a growth chamber with a diurnal temperature cycle gradually changing from $10^{\circ} \mathrm{C}$ at $0200 \mathrm{~h}$ to $15^{\circ} \mathrm{C}$ at $1400 \mathrm{~h}$ with a 16-h photoperiod provided by high pressure sodium lamps emitting $300 \mu \mathrm{mol}$ photon $\mathrm{s}^{-1} \mathrm{~m}^{-2}$.

Disease assessment. All rust phenotyping experiments were conducted in a completely randomized design and repeated at least once over time. Accessions exhibiting variable reactions across experiments were repeated in an additional experiment, if sufficient seeds were available.

Stem and leaf rust ITs on the Ae. longissima accessions were scored 12 days after inoculation using a 0 to 4 scale (Long and Kolmer 1989; Roelfs and Martens 1988; Stakman et al. 1962). Due to the slower development of the stripe rust pathogen in wheat, ITs were scored 19 days after inoculation using the 0 to 9 scale developed by Wan and Chen (2014).

Data analysis. For the summary of stem rust and leaf rust phenotype data, ITs were divided into two general reaction classes: resistant (ITs ranging from 0 to $2+$ ) and susceptible (ITs ranging from 3 - to 4). Similarly, stripe rust ITs ranging from 0 to 6 were classified as resistant and those from 7 to 9 as susceptible. Accessions were classified as heterogeneous if they included both resistant and susceptible plants. The percentage of accessions giving resistant, susceptible, and heterogeneous reactions to each rust race was calculated and presented in Table 3. To obtain general inferences on the geographic distribution of resistance and susceptibility of Ae. longissima in Israel, distribution maps were constructed with pie charts representing a single population or an aggregate of several populations.

Spatial analyses were performed to assess the geographic patterns of rust resistance in Ae. longissima across Israel. Spatial autocorrelation

Table 2. Race, isolate, virulence phenotype, and source of wheat rust pathogens used to evaluate resistance in Aegilops longissima

\begin{tabular}{|c|c|c|c|c|}
\hline Pathogen & Race $^{\mathbf{a}}$ & Isolate & Virulence/avirulence formula ${ }^{b}$ & Source \\
\hline Puccinia graminis f. sp. tritici & TTTTF & $02 \mathrm{MN} 84 \mathrm{~A}-1-2$ & $\begin{array}{l}\text { 5, 6, 7b, 8a, 9a, 9b, 9d, 9e, 9g, 10, 11, 17, 21, } \\
30,36,38, \text { McN, Tmp / 24, 31 }\end{array}$ & $\begin{array}{l}\text { Y. Jin (USDA-ARS Cereal Disease } \\
\text { Laboratory. St. Paul, MN) }\end{array}$ \\
\hline P. graminis f. sp. tritici & TTKSK & 04KEN156/04 & $\begin{array}{c}5,6,7 \mathrm{~b}, 8 \mathrm{a}, 9 \mathrm{a}, 9 \mathrm{~b}, 9 \mathrm{~d}, 9 \mathrm{e}, 9 \mathrm{~g}, 10,11,17,21, \\
30,31,38, \mathrm{McN} / 24,36, \mathrm{Tmp}\end{array}$ & $\begin{array}{l}\text { Y. Jin (USDA-ARS Cereal Disease } \\
\text { Laboratory. St. Paul, MN) }\end{array}$ \\
\hline P. triticina & THBJ & 99ND588DLL & $\begin{array}{l}\text { 1, 2a, 2c, 3a, 16, 26, 10, 14a, 18 / 9, 24, 3ka, } \\
11,17,30, \mathrm{~B}\end{array}$ & $\begin{array}{l}\text { J. Kolmer (USDA-ARS Cereal Disease } \\
\text { Laboratory. St. Paul, MN) }\end{array}$ \\
\hline P. triticina & BBBD & JAK & $\begin{array}{l}14 \mathrm{a} / 1,2 \mathrm{a}, 2 \mathrm{c}, 3 \mathrm{a}, 9,16,24,26,3 \mathrm{ka}, 11,17 \\
30, \mathrm{~B}, 10,18\end{array}$ & $\begin{array}{l}\text { J. Kolmer (USDA-ARS Cereal Disease } \\
\text { Laboratory. St. Paul, MN) }\end{array}$ \\
\hline P. striiformis f. sp. tritici & PSTv-37 & $10-106$ & $\begin{array}{l}6,7,8,9,17,27,43,44, \operatorname{Tr} 1, \operatorname{Exp} 2 / 1,5,10 \\
15,24,32, \text { SP, Tye }\end{array}$ & $\begin{array}{l}\text { X. Chen (USDA-ARS Wheat Genetics, } \\
\text { Physiology, Quality, and Disease Research } \\
\text { Unit and Department of Plant Pathology, } \\
\text { Washington State University, Pullman, WA) }\end{array}$ \\
\hline
\end{tabular}

\footnotetext{
${ }^{a}$ Races of the pathogens were characterized on the respective wheat differential host sets for stem rust (Jin et al. 2008; Roelfs and Martens 1988), leaf rust (Long and Kolmer 1989), and stripe rust (Wan and Chen 2014).

${ }^{b}$ The virulence/avirulence formulae represent the resistance genes of the differential wheat genotypes for which the pathogen races possess virulence or avirulence.
} 
refers to the correlation of a variable with itself in space (GeoDa 2017). To assess the degree of spatial autocorrelation for rust phenotypes among Ae. longissima accessions at neighboring collection sites, global spatial autocorrelation was measured using Global Moran's I in GeoDa (version 1.6.7). Values of Global Moran's I provide an overall assessment of whether a measured variable follows a clustered, dispersed, or random pattern in space (Esri 2017). Spatial weights matrices were constructed and used to impose a neighborhood structure on the data to assess the extent of similarity between location sites and values. Neighbors were defined by a binary $(0,1)$ and row-standardized spatial weights matrix in GeoDa (GeoDa 2017). The indices of Global Moran's I ranged from -1 to 1 . When the index is positive and closer to 1 , it indicates there is an overall pattern of similar phenotypic values being close together in space, i.e., high values at one site correlate with high values at neighboring sites (high-high relationship) or low values at one site correlate with low values at neighboring sites (low-low relationship). An index near 0 indicates a pattern of randomness for the measured phenotypic value. When the index is negative, it means there is an overall pattern of different phenotypic values being close together in space, i.e., high values at one site correlate with low values at a neighboring site (high-low relationship) and vice versa (low-high relationship) (GeoDa 2017). Global Moran's I was calculated from Moran's I Index value, and then a pseudo $P$-value was derived for each Global Moran's I using 999 permutations (GeoDa 2017). To prepare data for this analysis, the IT values of accessions at each collection site (ranging from 61 to 71 sites) within Israel were averaged to derive a single mean value. In ArcGIS (version 10.3.1) (Esri 2015), the accessions were geocoded to the coordinates provided in the World Geodetic System 1984 (WGS 84). Then, the dataset was reduced to include only one mean value per pair of identical coordinates. The resulting shapefile of each variable was projected into the Israel Transverse Mercator (in meters) for spatial analysis.

In addition to an overall assessment of clustering for phenotypic values in Ae. longissima as given by Global Moran's I, we also investigated whether local clusters occurred in the dataset. Local indicator of spatial association (LISA) (Anselin 1995) indicates the presence or absence of significant spatial clusters or outliers for each location. LISA maps are useful for assessing the hypothesis of spatial randomness and to identify local clusters. In the LISA analysis, a spatial weights matrix was generated for each variable using $\mathrm{GeoDa}$, comparing each site to its nearest four neighbors. For each point in space, LISA gives an indication of significant spatial clustering of a given variable. In the case of rust phenotypes, resistant-resistant, resistant-susceptible, susceptibleresistant, and susceptible-susceptible cluster types are possible.

\section{Results}

Uniform infection was obtained on all of the susceptible controls and Ae. longissima accessions to each of the rust pathogens. Additionally, the ITs exhibited by each accession to the respective pathogen races were, in most cases, similar between the two experiments conducted sequentially over time. In the few cases where the ITs were divergent, a third experiment was conducted to yield a consensus phenotype. The complete set of IT data for the Ae. longissima accessions are given in the supplementary tables.

Resistance to Puccinia graminis f. sp. tritici. A wide range of ITs (from 00; to 4) was observed on accessions in the Ae. longissima panel (Supplementary Table S2; Supplementary Fig. S1). The percentage of resistant accessions varied widely to the two races of P. graminis f. sp. tritici: over $80 \%$ were resistant to race TTKSK compared with only $18.2 \%$ to race TTTTF (Table 3 ). Among the accessions classified into the general category of resistance, 30.3 and $5.8 \%$ exhibited highly resistant ITs (0 to 0 ; ) in response to races TTKSK and TTTTF, respectively. The percentage of heterogeneous accessions (i.e., those with both resistant and susceptible plants) ranged from $4.2 \%$ to race TTKSK to $17.7 \%$ to race TTTTF (Table 3 ). Fifty-five accessions (22.4\%) exhibited resistance to both races of $P$. graminis f. sp. tritici.

Resistance to Puccinia triticina. As in the stem rust evaluations, the Ae. longissima accessions exhibited a wide range of ITs to $P$. triticina: from 00; to $3+4$ to both races THBJ and BBBD (Supplementary Table S3; Supplementary Fig. S1). The percentage of resistant accessions to the two races of $P$. triticina was comparable at $65.9 \%$ for THBJ and $52.2 \%$ for BBBD (Table 3). Among the accessions classified as resistant, 5.6 and $10.1 \%$ exhibited the highly resistant ITs of 0 to 0 ; to the respective races. The percentage of accessions exhibiting heterogeneous reactions was $13.9 \%$ to race THBJ and $18.5 \%$ to race BBBD (Table 3). One hundred and forty-nine accessions (45.8\%) exhibited resistance to both races of P. triticina.

Resistance to Puccinia striiformis f. sp. tritici. The Ae. longissima accessions exhibited the full range of ITs (1 to 9) to P. striiformis f. sp. tritici race PSTv-37 (Supplementary Table S4; Supplementary Fig. S1). Half (50.1\%) of the collection was resistant to race PSTv-37 (Table 3), and of this group, $42.5 \%$ exhibited highly resistant ITs of 0 to 2 . The percentage of accessions showing heterogeneous reactions to $P$. striiformis f. sp. tritici was low at $6.6 \%$.

The Ae. longissima accessions displayed different combinations of resistance to the three rust pathogens. Ten accessions (AEG-683-23, AEG-725-15, AEG-803-49, AEG-1274-20, AEG-1276-22, AEG1471-15, AEG-1475-19, AEG-2974-0, AEG-4005-20, and AEG8705-10) were resistant to all races of the three rust pathogens tested in this study; 21 were resistant to both races of $P$. graminis $\mathrm{f}$. sp. tritici and both races of $P$. triticina; 18 were resistant to both races of $P$. graminis f. sp. tritici and $P$. striiformis f. sp. tritici; and 86 were resistant to both races of $P$. triticina and $P$. striiformis f. sp. tritici. In contrast, only three accessions (AEG-5002-5, AEG-8770-25, and AEG-9654-8) were susceptible to all of the three pathogens.

Although the number of Ae. longissima accessions collected from different sites within Israel was quite variable, distinct differences in the geographic distribution of resistance and susceptibility were noted to some rust races from inspection of the distribution maps. For example, to $P$. graminis f. sp. tritici race TTKSK, populations with a very high frequency of resistance were concentrated in the central and northern part of Israel, and populations with a comparatively higher frequency of susceptibility were concentrated in the southern part of the country (Fig. 2). A somewhat similar trend was observed to race TTTTF, but with a moderate frequency of resistance in populations from the central/north region and a very high frequency of susceptibility in populations from the south (Supplementary Fig. S2). The relative proportion of resistant to susceptible Ae. longissima accessions to $P$. triticina in populations across Israel was generally similar, with resistance predominating in most cases

Table 3. Number and percentage of Aegilops longissima accessions exhibiting resistant, susceptible, and heterogeneous reactions to three wheat rust pathogens

\begin{tabular}{|c|c|c|c|c|c|}
\hline Pathogen & Race & Resistant $^{\mathbf{a}}$ & Susceptible $^{b}$ & Heterogeneous $^{c}$ & Total \\
\hline Puccinia graminis f. sp. tritici & TTTTF & $64(18.2 \%)$ & $225(64.1 \%)$ & $62(17.7 \%)$ & $351(100 \%)$ \\
\hline P. graminis f. sp. tritici & TTKSK & $249(80.8 \%)$ & $46(14.9 \%)$ & $13(4.2 \%)$ & $308(100 \%)$ \\
\hline P. triticina & THBJ & $247(65.9 \%)$ & $76(20.3 \%)$ & $52(13.9 \%)$ & $375(100 \%)$ \\
\hline P. triticina & BBBD & $178(52.2 \%)$ & $100(29.3 \%)$ & $63(18.5 \%)$ & $341(100 \%)$ \\
\hline P. striiformis f. sp. tritici & PSTv-37 & $190(50.1 \%)$ & $164(43.3 \%)$ & $25(6.6 \%)$ & $379(100 \%)$ \\
\hline
\end{tabular}

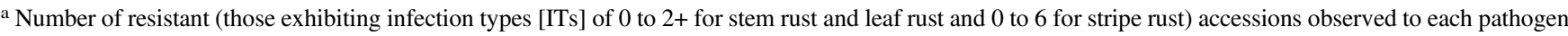
race. The frequency of resistance is given in parentheses.

${ }^{b}$ Number of susceptible (those exhibiting ITs of 3- to 4 for stem rust and leaf rust and 7 to 9 for stripe rust) accessions observed to each pathogen race. The frequency of susceptibility is given in parentheses.

${ }^{\mathrm{c}}$ Heterogeneous indicates that individual accessions exhibited a mixture of distinctly resistant and susceptible plants. 
(Supplementary Figs. S3 and S4). To P. striiformis f. sp. tritici race PSTv-37, populations with a very high frequency of resistance were concentrated in the southern part of Israel, and populations with a comparatively higher frequency of susceptibility were concentrated in the central and northern part of the country (Fig. 3). For the Ae. longissima populations in southern Israel, the very high frequency of resistance to race PSTV-37 contrasted greatly with the relatively high frequency of susceptibility to race TTTTF.

Spatial autocorrelation and LISA analyses. The null hypothesis for spatial autocorrelation as assessed by Global Moran's I statistic is that the rust phenotypes of Ae. longissima accessions are randomly distributed among the collection sites in Israel. In four of the five cases involving the different rust races (all except $P$. triticina race BBBD), the null hypothesis was rejected as the $P$-values were statistically significant at $P<0.05$ or $P<0.001$ (Table 4 ). The highest level of spatial autocorrelation (i.e., clustering of accessions with similar rust phenotypes) found was with the two races of $P$. graminis $\mathrm{f}$. sp. tritici, both with a Global Moran's I value of 0.42 . The next highest value of Global Moran's I (0.34) was observed for $P$. striiformis $\mathrm{f}$. sp. tritici, again indicating a high degree of clustering of accessions with similar rust phenotypes. Finally, a moderate degree of clustering was observed for $P$. triticina rust phenotypes with races THBJ and BBBD having Global Moran's I values of 0.19 and 0.12, respectively. However, as mentioned above, the null hypothesis was not rejected for data to race $\mathrm{BBBD}$.

In addition to calculating Global Moran's I as an overall assessment of whether the rust phenotypes follow a clustered, dispersed, or random pattern in space, LISA analyses also were done to assess the presence or absence of significant spatial clusters or outliers for each location. Broadly separated groups of resistant-resistant and susceptible-susceptible cluster types were observed in Ae. longissima to four of the five rust pathogen races (Figs. 4 and 5; Supplementary Figs. S5 and S6), the exception being $P$. triticina race BBBD (Supplementary Fig. S7). The most strikingly divergent patterns of spatial clustering were with $P$. graminis $\mathrm{f}$. sp. tritici race TTKSK and $P$. striiformis f. sp. tritici race PSTv-37. With the former, significant spatial clustering of resistance (almost exclusively the resistantresistant cluster type) was observed in a $\sim 356 \mathrm{~km}^{2}$ area along the coastal plain between the cities of Ashdod and Hadera, and significant clustering of susceptibility (almost exclusively the susceptiblesusceptible cluster type) was observed in a $\sim 378 \mathrm{~km}^{2}$ area northwest of Be'er Sheva and a $\sim 496 \mathrm{~km}^{2}$ area between Be'er Sheva and Sde Boker (Fig. 4). For P. striiformis f. sp. tritici race PSTv-37, the pattern of spatial clustering was reversed: significant spatial clustering

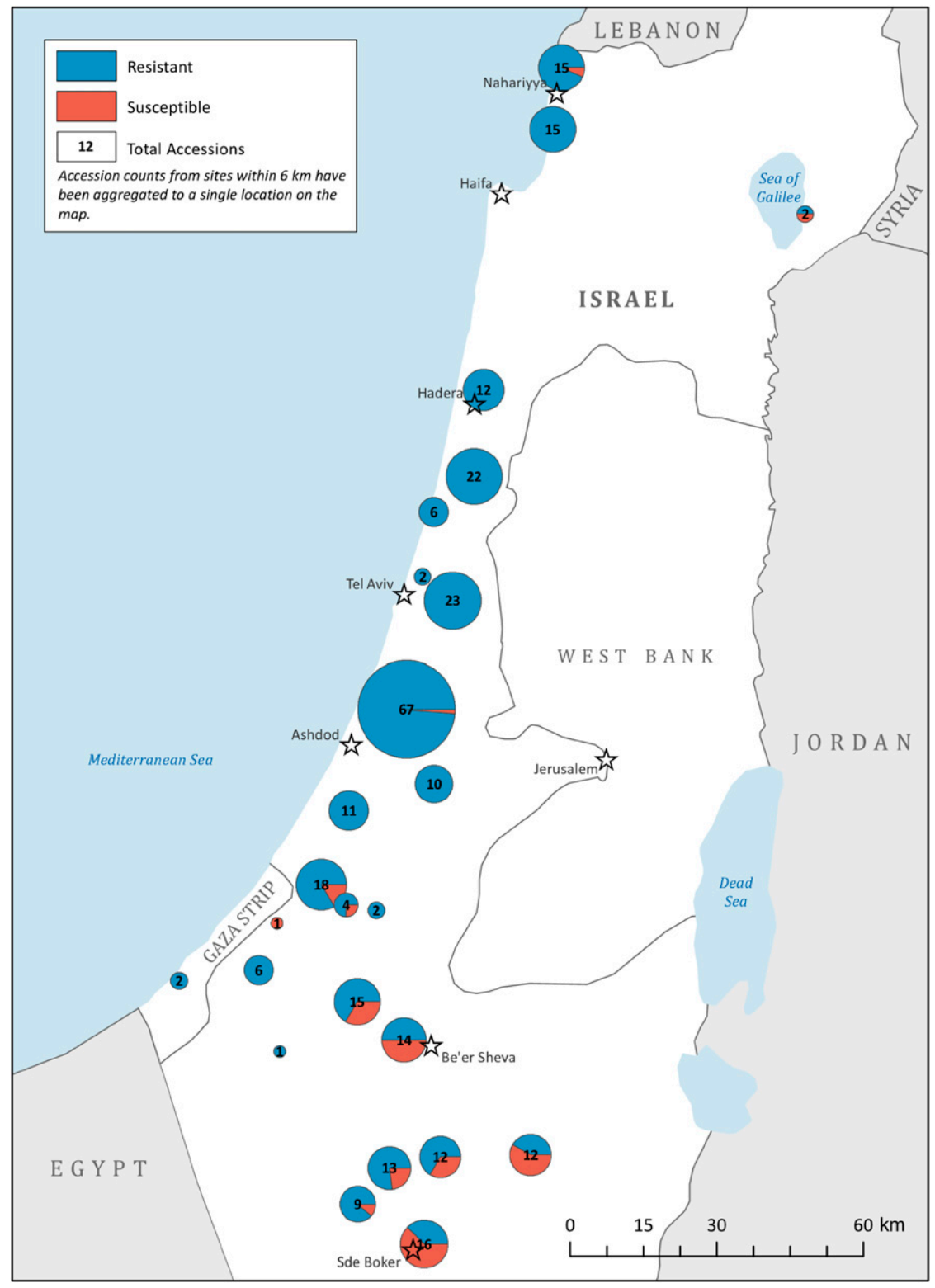

Fig. 2. Map of Israel showing the geographic distribution of Aegilops longissima accessions resistant and susceptible to Puccinia graminis f. sp. tritici race TTKSK. 
of susceptibility (mostly the susceptible-susceptible cluster type) was observed in a $\sim 758 \mathrm{~km}^{2}$ area along the coastal plain between the cities of Ashdod and Hadera, whereas clustering of resistance (almost exclusively the resistant-resistant cluster type) was found in a $\sim 409 \mathrm{~km}^{2}$ area northwest of Be'er Sheva and a $\sim 523 \mathrm{~km}^{2}$ area between Be'er Sheva and Sde Boker (Fig. 5). The spatial clustering of resistant-resistant and susceptible-susceptible cluster types to $P$. graminis f. sp. tritici race TTTTF and $P$. triticina race THBJ was generally similar to that found for race TTKSK; however, there were many more cases of resistant-susceptible and susceptibleresistant cluster types being present (Supplementary Figs. S5 and S6). Only one significant cluster (susceptible-resistant cluster type) was found with $P$. triticina race BBBD and that was southeast of Ashdod (Supplementary Fig. S7).

\section{Discussion}

Virulence changes in $P$. graminis $\mathrm{f}$. sp. tritici, $P$. triticina, and $P$. striiformis f. sp. tritici present one of the greatest challenges for achieving durable control of rust diseases in wheat. When single resistance genes are deployed in widely grown cultivars, rust pathogens can easily overcome these resistances through single mutations, leading to widespread epidemics. As the reservoir of readily accessible resistance genes from the primary gene pool of wheat is depleted, the secondary gene pool has gained increasing importance as a source of new resistances. Ae. longissima is a member of the secondary gene pool of wheat and is vastly underutilized as a source of disease resistance genes. In this study, a diverse collection of Ae. longissima accessions, mostly from Israel, was evaluated for seedling resistance to the three rust diseases of wheat. The results clearly show that Ae. longissima is a rich and diverse source of resistance to the stem, leaf,

Table 4. Degree of spatial autocorrelation for rust phenotypes of Aegilops longissima between collection sites in Israel as assessed by Global Moran's I

\begin{tabular}{llccc}
\hline Pathogen & Race & $\begin{array}{c}\text { Number of } \\
\text { sites analyzed }\end{array}$ & $\begin{array}{c}\text { Global } \\
\text { Moran's I }\end{array}$ & P-value \\
\hline $\begin{array}{l}\text { Puccinia graminis } \\
\text { f. sp. tritici }\end{array}$ & TTTTF & 73 & 0.42 & $<0.001$ \\
P. graminis f. sp. tritici & TTKSK & 61 & 0.42 & $<0.001$ \\
P. triticina & THBJ & 73 & 0.19 & $<0.05$ \\
P. triticina & BBBD & 70 & 0.12 & $>0.05$ \\
P. striiformis f. sp. tritici & PSTv-37 & 72 & 0.34 & $<0.001$ \\
\hline
\end{tabular}

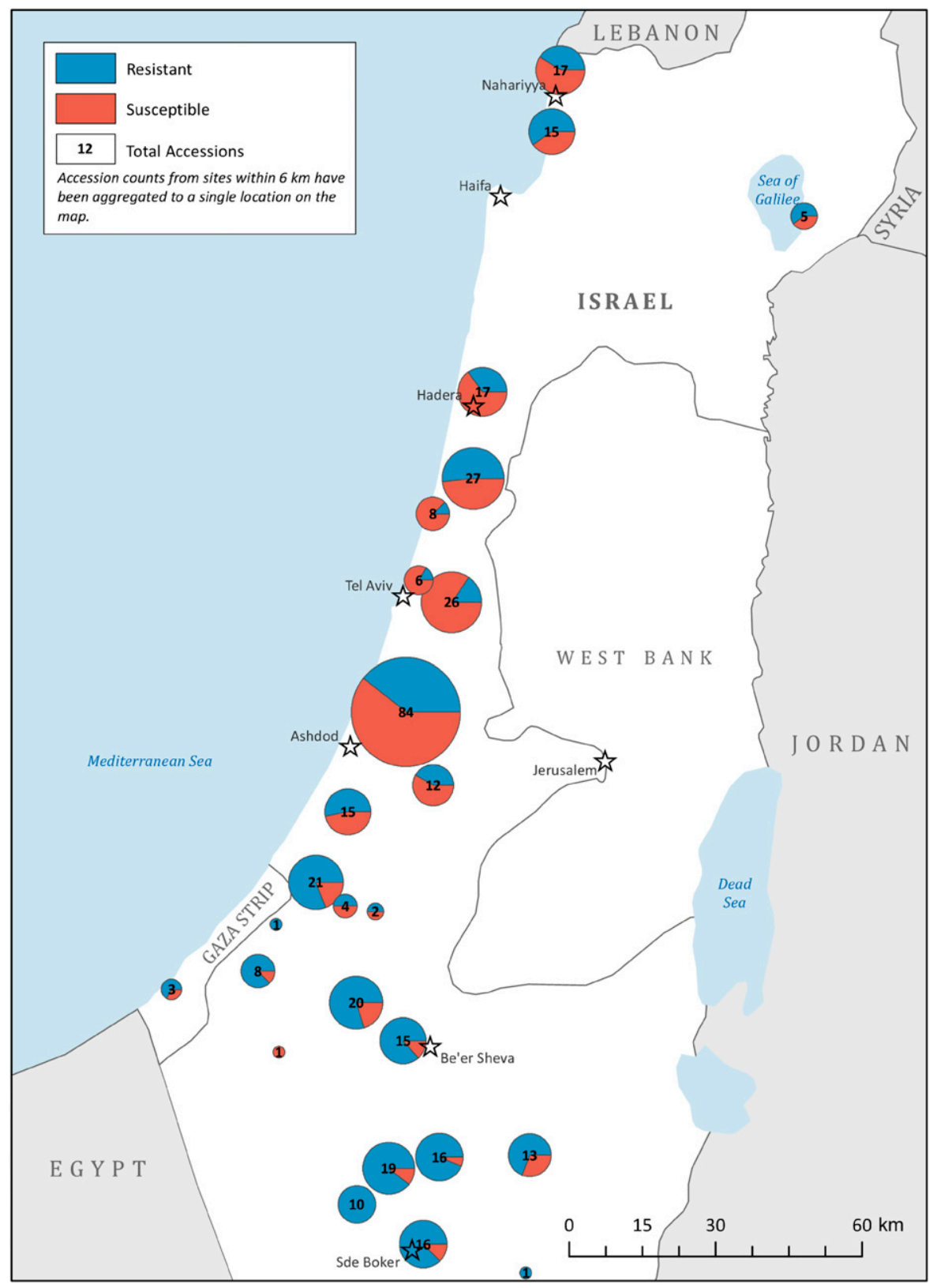

Fig. 3. Map of Israel showing the geographic distribution of Aegilops Iongissima accessions resistant and susceptible to Puccinia striiformis f. sp. tritici race PSTv-37. 
and stripe rust diseases. With respect to $P$. graminis $\mathrm{f}$. $\mathrm{sp}$. tritici race TTKSK, the original virulence type of the $\mathrm{Ug} 99$ race group from Africa, over $80 \%$ of the Ae. longissima accessions were resistant (Table 3) with nearly one third of these resistant accessions exhibiting very low ITs of 0 or 0 ; (Supplementary Table S2). The high frequency of resistance to race TTKSK in this study $(80.2 \%)$ was similar to that found by Scott et al. (2014) (84\%), who screened many of the same accessions in their stem rust evaluations of 10 Aegilops species. They also reported a high frequency of resistance (97\%) in these same Ae. longissima accessions to two other members of the $\mathrm{Ug} 99$ race group: TTKST and TTTSK. These combined results demonstrate the great potential of Ae. longissima as a source of new resistance genes against the Ug99 group races. A comparable high frequency of resistance $(\sim 70 \%)$ to race TTKSK was also reported for the closely related species Ae. sharonensis by Olivera et al. (2007). In contrast to the race TTKSK results, the frequency of resistance to the widely virulent domestic race of TTTTF was markedly lower at just $18.2 \%$ (Table 3), indicating strong race specificity of stem rust resistance genes in $A e$. longissima.
From the leaf rust evaluations, moderately high frequencies of resistance were found in Ae. longissima after challenge with races THBJ (65.9\%) and BBBD (52.2\%) (Table 3). Additionally, accessions exhibiting highly resistant ITs were nearly twice as common with the former race $(10.1 \%)$ than the latter race $(5.6 \%)$ (Supplementary Table S3). The frequency of leaf rust resistance found in this study was higher than that found previously for Ae. longissima accessions from Israel by Anikster et al. (2005). In that study, 379 accessions were tested against the U.S. races SBDB and TBBL, and 39\% were found resistant. In another test with a composite of 12 domestic races of $P$. triticina, Anikster et al. (2005) found $37 \%$ of the accessions resistant. Olivera et al. (2007) investigated the resistance of Ae. sharonensis to the same $P$. triticina races of THBJ and BBBD (mistakenly labeled BBBB in their study) used in this study and found very similar resistance frequencies of 62.6 and $59.8 \%$, respectively. This result was not unexpected given the close genetic relationship between the two species.

The Ae. longissima accessions were also evaluated to the most widely distributed $P$. striiformis $\mathrm{f}$. sp. tritici race in the United States (PSTv-37), and over half (50.1\%) were found resistant (Table 3).

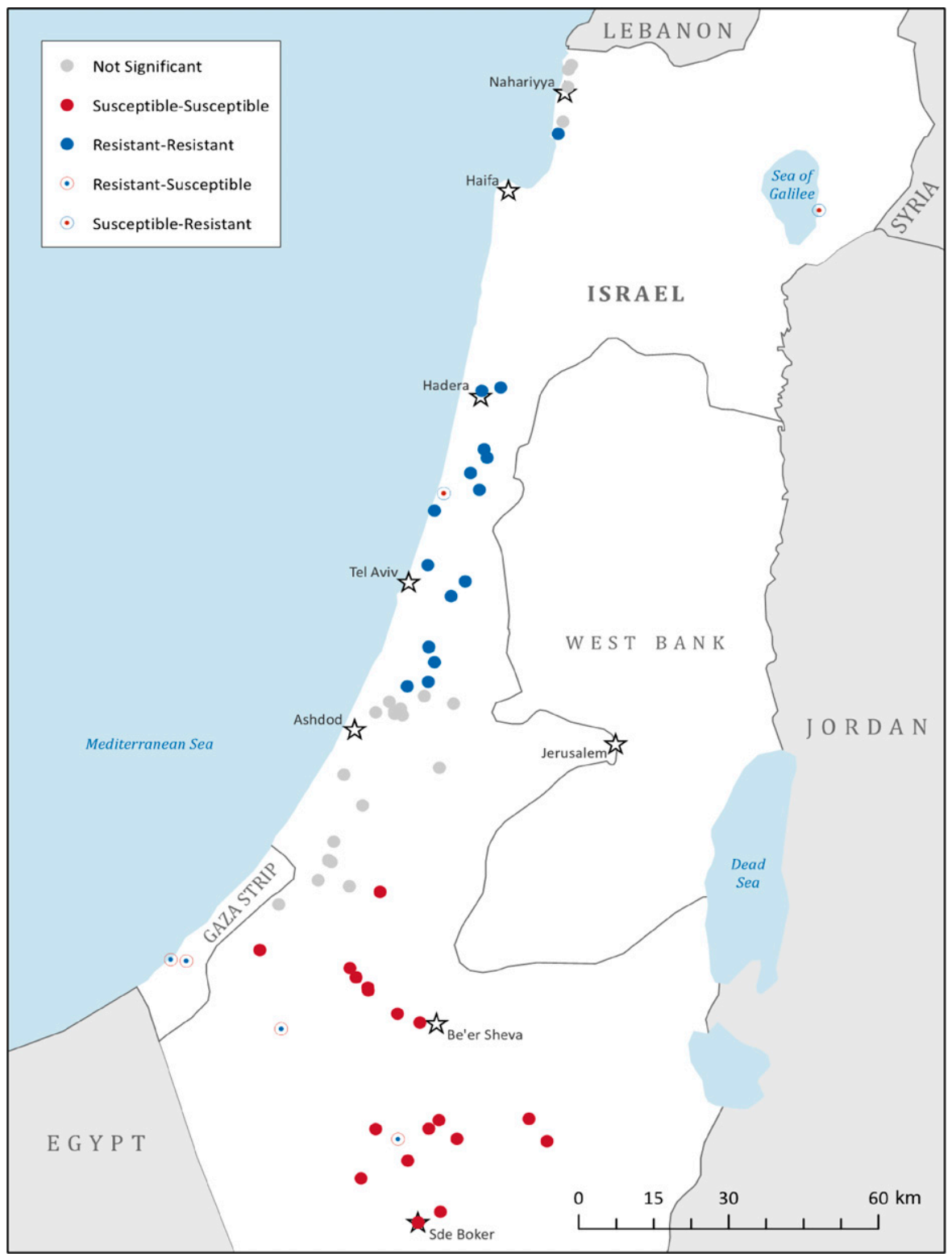

Fig. 4. Map of Israel showing the local indicator of spatial association (LISA) clusters of Aegilops longissima accessions in response to infection by Puccinia graminis f. sp. tritici race TTKSK. For the LISA analysis, a spatial weights matrix was generated for each variable using GeoDa, comparing each site to its nearest four neighbors. Susceptible-susceptible indicates significant clusters of neighboring accessions exhibiting susceptible reactions; resistant-resistant indicates significant clusters of neighboring accessions exhibiting resistant reactions; resistant-susceptible indicates significant clusters of neighboring accessions exhibiting resistant and also susceptible reactions; and susceptible-resistant indicates significant clusters of neighboring accessions exhibiting susceptible and also resistant reactions. 
Moreover, a substantially high percentage (42.5\%) of these resistant accessions exhibited very low ITs (0 to 2 ) (Supplementary Table S4). Anikster et al. (2005) assessed the resistance of 512 Ae. longissima accessions to stripe rust in the field in Israel and found $91 \%$ were resistant. In that study, most accessions showed low rust severities of 1 to $2 \%$, yet a few exhibited highly resistant ITs (ITs $=0$ to 2 ), indicative of a hypersensitive response. In a greenhouse study done on seedlings of Ae. sharonensis, Olivera et al. (2007) found 48 of 107 (44.9\%) accessions resistant to $P$. striiformis f. sp. tritici race PST-78.

Ae. longissima is mostly a self-pollinating species, but some outcrossing can occur in nature, resulting in heterozygous loci that segregate. For this investigation, we made single plant selections for each Ae. longissima accession and then self-pollinated them from one to four generations to increase homozygosity and generate sufficient seed stocks for the experiments. The percentage of Ae. longissima accessions showing heterogeneous reactions to the rusts ranged from $4.2 \%$ to race TTKSK of $P$. graminis $\mathrm{f}$. $\mathrm{sp}$. tritici to $18.5 \%$ to race BBBD of $P$. triticina (Table 3 ). This range in the level of heterogeneous reactions is quite similar to that found in Ae. sharonensis (Olivera et al.
2007) to many of the same pathogen races used in this study and is common in wild cereal relatives.

The geographic distribution of rust phenotypes in Ae. longissima was characterized across Israel through i) overall spatial autocorrelation analysis using Global Moran's I, ii) inspection of distribution maps, and iii) LISA analyses of local populations. In four of the five cases involving the different rust races (all except $P$. triticina race BBBD), statistically significant spatial autocorrelation was found (Table 4). The highest level of spatial autocorrelation found was with the two races of $P$. graminis f. sp. tritici, followed by $P$. striiformis f. sp. tritici. The high positive values found for Global Moran's I ( 0.34 to 0.42 ) in these three cases indicate a clustering of accessions with similar rust phenotypes. A moderate degree of clustering was observed for $P$. triticina phenotypes, with races THBJ and BBBD having Global Moran's I values of 0.19 and 0.12 , respectively. However, the null hypothesis for the random distribution of rust phenotypes to race BBBD was not rejected. Distribution maps (Figs. 2 and 3) and LISA maps (Figs. 4 and 5) provide assessments for specific spatial patterns of rust phenotypes in Ae. longissima. LISA maps are more robust because they provide statistical validation and a more

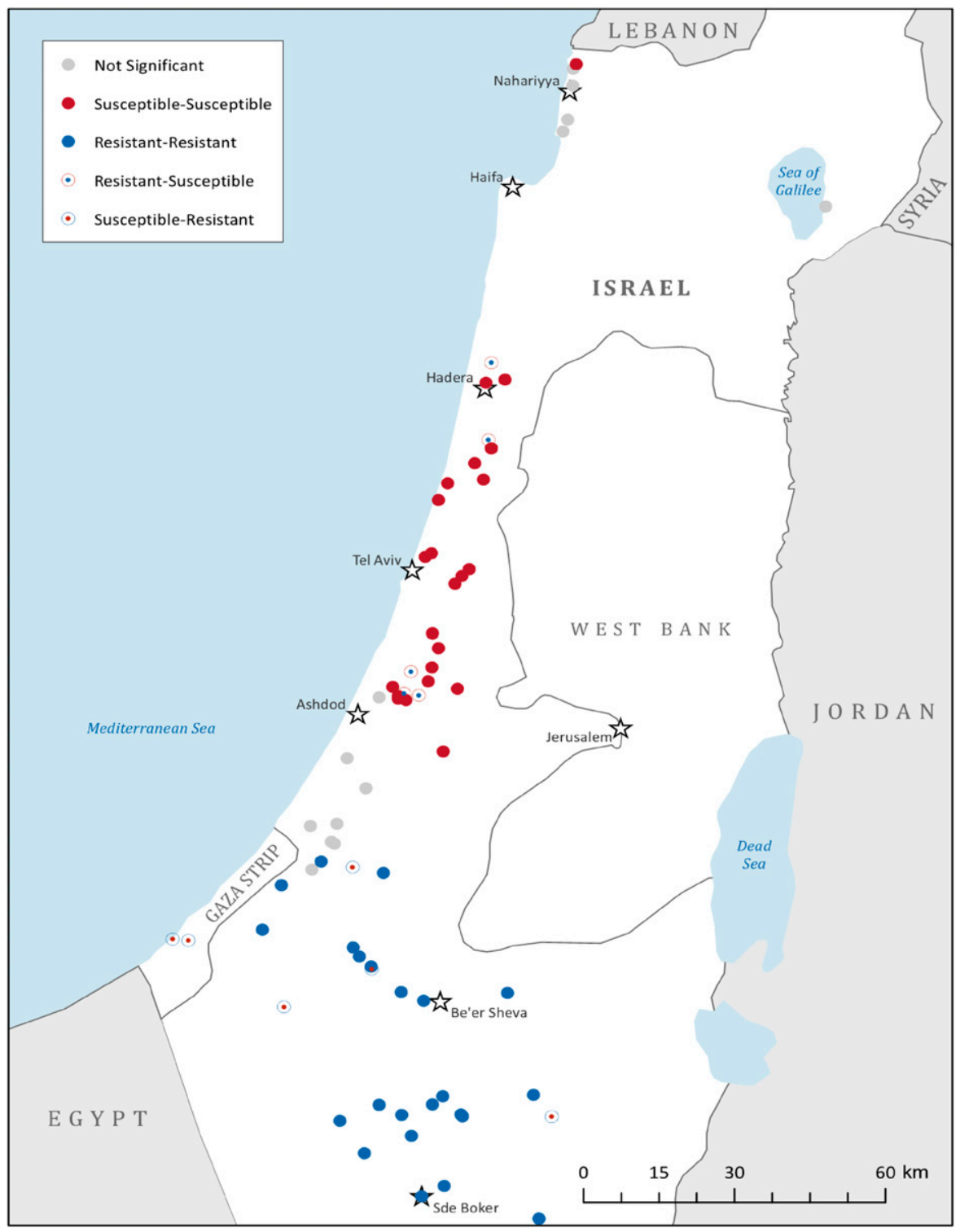

Fig. 5. Map of Israel showing the local indicator of spatial association (LISA) clusters of Aegilops longissima accessions in response to infection by Puccinia striiformis f. sp. tritici race PSTv-37. For the LISA analysis, a spatial weights matrix was generated for each variable using GeoDa, comparing each site to its nearest four neighbors. Susceptiblesusceptible indicates significant clusters of neighboring accessions exhibiting susceptible reactions; resistant-resistant indicates significant clusters of neighboring accessions exhibiting resistant reactions; resistant-susceptible indicates significant clusters of neighboring accessions exhibiting resistant and also susceptible reactions; and susceptibleresistant indicates significant clusters of neighboring accessions exhibiting susceptible and also resistant reactions. 
definitive visualization of the spatial clustering types (i.e., resistantresistant, resistant-susceptible, susceptible-susceptible, and susceptibleresistant). With respect to $P$. graminis f. sp. tritici, Ae. longissima populations with a very high (race TTKSK) to moderately high (race TTTTF) frequency of resistance were concentrated in the central and northern part of Israel where the rainfall is higher, whereas populations with a moderately high (race TTKSK) to very high (TTTTF) frequency of susceptibility were concentrated in the southern part of the country (including the Negev Desert) where rainfall is low $(<600 \mathrm{~mm})$ (Fig. 2; Supplementary Fig. S2). The LISA map clearly revealed the predominance of the resistant-resistant and susceptible-susceptible cluster types and their north/south divide to race TTKSK (Fig. 4). The general distribution pattern of resistance found to races TTKSK and TTTTF in this study was similar to that observed by Scott et al. (2014) to the domestic Israeli race of TTTTC, providing some validation for this earlier result. The relative proportion of resistant to susceptible accessions in Ae. longissima populations to $P$. triticina (both THBJ and BBBD) was generally similar across Israel based on the distribution maps (Supplementary Figs. S3 and S4). The LISA map for race THBJ revealed resistant-resistant clustering in the central region and susceptible-susceptible clustering in the southern region of the country; however, there were many cases of susceptible-resistant and resistant-susceptible cluster types also present (Supplementary Fig. S6). To race BBBD, LISA revealed only one significant cluster (susceptible-resistant, east of Ashdod) across all populations in Israel (Supplementary Fig. S7). Another distinct geographic pattern of resistance in Ae. longissima was found for $P$. striiformis f. sp. tritici race PSTv-37. However, in this case, the trend was opposite to that observed for stem rust races TTKSK and TTTTF: populations with a very high frequency of resistance were concentrated in the southern part of Israel, whereas populations with a comparatively higher frequency of susceptibility were concentrated in the central and northern part of the country (Fig. 3). In the Ae. longissima populations of the south, the very high frequency of resistance to race PSTv-37 contrasted greatly with the very high frequency of susceptibility to race TTTTF.

It is difficult to explain the basis of the distinct geographic patterns found for resistance to the different rust pathogens, especially $P$. graminis f. sp. tritici race TTKSK versus $P$. striiformis f. sp. tritici race PSTv-37. One cannot easily attribute the observed concentration of stem rust resistance in central/northern Israel solely to more intense coevolutionary disease selection pressure mediated by higher levels of precipitation. The distribution of rust diseases naturally occurring on Ae. longissima in Israel has not been adequately studied. However, it is known that stem rust of cultivated wheat occurs most frequently in southern Israel and infrequently in the central/northern coastal plains where largely resistant populations of Ae. longissima predominate (H. Sela, unpublished). With stripe rust, the highest frequency of resistance found in Ae. longissima was in the south. The southern part of Israel (including the Negev Desert) has lower minimum temperatures and possibly more frequent dew periods that might favor the development of this "cool season" rust disease early in the vegetative growth period of the host plant. If such conditions did occur over a long time, there would be selection pressure for resistance in Ae. longissima. Alternatively, the patterns of concentration for resistance found for both stem rust and stripe rust might be due to some other unknown associated adaptive trait with the clustering caused by limited gene flow. The distinct patterns of spatial clustering for rust phenotypes are intriguing and should be investigated further by evaluating additional $A e$. longissima accessions at the intersection between clusters having distinct rust phenotypes, determining the genetic relationships among accessions by molecular markers, exploring other adaptive characters that might be associated with rust resistance, and investigating environmental/ecological factors that might influence the evolution of rust resistance in the species.

To efficiently exploit the most widely effective rust resistance genes from Ae. longissima for wheat improvement, additional rust evaluations and genetic studies should be completed. On the short list for such studies are the 10 accessions that were resistant to all races of the three pathogens investigated in this study. Studies are underway to investigate the resistance spectrum of these 10 accessions to a large and diverse panel of rust virulence types at both the seedling and adult plant stages. Aside from these 10 select accessions, there are other accessions with valuable resistance to multiple rust pathogens worthy of further investigation. For example, 21 accessions were resistant to both races of $P$. graminis f. sp. tritici and both races of $P$. triticina; 18 were resistant to both races of $P$. graminis f. sp. tritici and $P$. striiformis $\mathrm{f}$. sp. tritici; and 86 were resistant to both races of $P$. triticina and $P$. striiformis f. sp. tritici.

Our long-term goal is to transfer rust resistance genes from Ae. longissima into wheat. This process is difficult and time-consuming using standard wide-hybridization techniques because of inherent low crossability between the species, low homeologous pairing, the "hitch-hiking" of deleterious genes along with target genes in the introgressed segments (i.e., linkage drag), and gametocidal genes (Endo 1985; Millet 2007). Nevertheless, a number of disease resistance genes have been transferred from Ae. longissima and its closely related sympatric species Ae. sharonensis into wheat via this technique. A dominant gene for resistance to powdery mildew (Pm13) was transferred from Ae. longissima into wheat cv. Chinese Spring using the wheat phl mutant to induce homeologous recombination (Ceoloni et al. 1992). With respect to Ae. sharonensis, Lr56 for leaf rust resistance and $Y r 38$ for stripe rust resistance have been successfully transferred into wheat using wide-hybridization techniques (Marais et al. 2010). Leaf rust and stripe rust resistance genes were also transferred from Ae. sharonensis accession TH548 into wheat by Millet et al. (2014), but their relation to those described by Marais et al. (2010) is currently unknown.

The direct cloning of resistance genes from Aegilops species and their transfer into wheat via various transformation protocols represents a promising alternative to wide-hybridization techniques. This technology can eliminate the problem of linkage drag and also facilitate the strategy of resistance gene stacking or pyramiding (Wulff and Moscou 2014). Recently, Steuernagel et al. (2016) described a three-step protocol called mutagenesis resistance gene enrichment sequencing (MutRenSeq) for rapidly isolating resistance genes from plants. This protocol is based on chemical (ethyl methanesulfonate) mutagenesis of the resistance sources and subsequent screening for susceptibility mutants; exome capture and sequencing of resistance gene family members; and sequence comparisons of wild type and susceptibility mutants. As a proof of concept, Steuernagel et al. (2016) used MutRenSeq to clone the stem rust resistance genes $S r 22$ (originally derived from $T$. monococcum) and $S r 45$ (originally derived from Ae.tauschii) from wheat introgression lines. We applied MutRenSeq directly to the wild wheat species Ae. sharonensis (not a wheat line carrying a resistance gene introgressed from a wild species) and recovered several stem rust susceptibility mutants. These mutants are now being sequenced for comparison with the wild type sequence in order to identify the causal resistance gene (B. Steffenson and B. Wulff, unpublished). With additional effort, MutRenSeq and potentially other advanced cloning protocols will facilitate the isolation of many new rust resistance genes from Aegilops in the near future. This development, coupled with new transformation protocols that can transfer three to four genes on a single construct at a time into wheat, hold great promise for the gene pyramiding strategy and more durable control of rust diseases.

\section{Acknowledgments}

We thank Harold Bockleman, curator of the USDA-ARS National Small Grains Collection, for providing some of the germplasm used in this study; Oadi Matny, Tamas Szinyei, Yuan Chai, Katie Ring, Beth Harries, Ryan Gavin, Sofi Klausner, and Moran Nave for excellent technical assistance and Matthew Martin for preparation of figures. Data analysis support was provided by the University of Minnesota U-Spatial group led by Len Kne.

\section{Literature Cited}

Anselin, L. 1995. Local indicators of spatial association-LISA. Geogr. Anal. 27:93-115. Anikster, Y., Manisterski, J., Long, D. L., and Leonard, K. J. 2005. Resistance to leaf rust, stripe rust, and stem rust in Aegilops spp. in Israel. Plant Dis. 89:303-308.

ArcGIS Resources. 2017. http://resources.arcgis.com/en/home/.

Beddow, J. M., Pardey, P. G., Chai, Y., Hurley, T. M., Kriticos, D. J., Braun, H., Park, R. F., Cuddy, W. S., and Yonow, T. 2015. Research investment implications of shifts in the global geography of wheat stripe rust. Nat. Plants 132:1-5.

Bolton, M. D., Kolmer, J. A., and Garvin, D. F. 2008. Wheat leaf rust caused by Puccinia triticina. Mol. Plant Pathol. 9:563-575.

Borlaug Global Rust Initiative (BGRI). 2017. Online resource: https://www. globalrust.org/. 
Cenci, A., D'Ovidio, R., Tanzarella, O. A., Ceoloni, C., and Porceddu, E. 1999. Identification of molecular markers linked to Pm13, an Aegilops longissima gene conferring resistance to powdery mildew in wheat. Theor. Appl. Genet. 98:448-454.

Ceoloni, C., Signore, G. D., Ercoli, L., and Donini, P. 1992. Locating the alien chromatin segment in common wheat-Aegilops longissima mildew resistant transfers. Hereditas 116:239-245.

Chen, X. M. 2007. Challenges and solutions for stripe rust control in the United States. Aust. J. Agric. Res. 58:648-655

Dakouri, A., McCallum, B. D., Radovanovic, N., and Cloutier, S. 2013. Molecular and phenotypic characterization of seedling and adult plant leaf rust resistance in a world wheat collection. Mol. Breed. 32:663-677.

Donini, P., Koebner, R. M. D., and Ceoloni, C. 1995. Cytogenetic and molecular mapping of the wheat-Aegilops longissima chromatin breakpoints in powdery mildew-resistant introgression lines. Theor. Appl. Genet. 91:738-743.

Ecker, R., Cahaner, A., and Dinoor, A. 1990. The inheritance of resistance to Septoria glume blotch. Plant Breed. 104:224-230.

Ellis, J. G., Lagudah, E. S., Spielmeyer, W., and Dodds, P. N. 2014. The past, present and future of breeding rust resistant wheat. Front. Plant Sci. 5:641.

Endo, T. R. 1985. Two types of gametocidal chromosomes of Aegilops sharonensis and Ae. longissima. Jpn. J. Genet. 60:125-135.

Esri. 2015. ArcGIS Desktop, Release 10.3.1. Environmental Systems Research Institute (Esri), Redlands, CA.

Esri. 2017. Spatial Autocorrelation (Global Moran's I). ArcMap 10.3. Environmental Systems Research Institute (Esri), Redlands, CA. http://desktop. arcgis.com/en/arcmap/10.3/tools/spatial-statistics-toolbox/spatial-autocorrelation. htm

Feuillet, C., Langridge, P., and Waugh, R. 2008. Cereal breeding takes a walk on the wild side. Trends Genet. 24:24-32.

Friebe, B., Jiang, J., Raupp, W. J., Mclntosh, R. A., and Gill, B. S. 1996. Characterization of wheat-alien translocations conferring resistance to diseases and pests: Current status. Euphytica 91:59-87.

GeoDa. 2017. An Introduction to Spatial Data Analysis 1.10. http://geodacenter. github.io/index.htm

Harlan, J. R., and de Wet, J. M. J. 1971. Toward a rational classification of cultivated plants. Taxon 20:509-517.

Huang, S. 2016. Phenotypic diversity in the wheat wild relative Aegilops longissima. M.S. thesis, University of Minnesota, St. Paul, MN.

Jin, Y., Szabo, L. J., Pretorius, Z. A., Singh, R. P., Ward, R., and Fetch, T., Jr. 2008. Detection of virulence to resistance gene $S r 24$ within race TTKS of Puccinia graminis f. sp. tritici. Plant Dis. 92:923-926.

Kilian, B., Özkan, H., Deusch, O., Effgen, S., Brandolini, A., Kohl, J., Martin, W., and Salamini, F. 2007. Independent wheat B and G genome origins in outcrossing Aegilops progenitor haplotypes. Mol. Biol. Evol. 24:217-227.

Kimber, G., and Feldman, M. 1987. Wild Wheat: An Introduction, Special Report 353. College of Agriculture, University of Missouri, Columbia, MO.

Klindworth, D. L., Niu, Z., Chao, S., Friesen, T. L., Jin, Y., Faris, J. D., Cai, X., and Xu, S. S. 2012. Introgression and characterization of a goatgrass gene for a high level of resistance to Ug99 stem rust in tetraploid wheat. G3 (Bethesda) 2:665-673.

Kolmer, J. A., Long, D. L., and Hughes, M. E. 2007. Physiologic specialization of Puccinia triticina on wheat in the United States in 2005. Plant Dis. 91:979-984.

Li, Q., Chen, X. M., Wang, M. N., and Jing, J. X. 2011. Yr45, a new wheat gene for stripe rust resistance on the long arm of chromosome 3D. Theor. Appl. Genet. 122:189-197.

Liu, W., Jin, Y., Rouse, M., Friebe, B., Gill, B., and Pumphrey, M. O. 2011. Development and characterization of wheat-Ae. searsii Robertsonian translocations and a recombinant chromosome conferring resistance to stem rust. Theor. Appl. Genet. 122:1537-1545.

Long, D. L., and Kolmer, J. A. 1989. A North American system of nomenclature for Puccinia triticina f. sp. tritici. Phytopathology 79:525-529.

Marais, G. F., Badenhorst, P. E., Eksteen, A., and Pretorius, Z. A. 2010. Reduction of Aegilops sharonensis chromatin associated with resistance genes Lr56 and Yr38 in wheat. Euphytica 171:15-22.

Markell, S. G., and Milus, E. A. 2008. Emergence of a novel population of Puccinia striiformis f. sp. tritici in eastern United States. Phytopathology 98:632-639.

McIntosh, R. A. 1991. Alien sources of disease resistance in bread wheats. Pages 320-332 in: Proc. Dr. H. Kihara Memorial International Symposium on Cytoplasmic Engineering in Wheat. Nuclear and organellar genomes of wheat species. T. Sasakuma and T. Kinoshita, eds. 3-6 July 1991, Hokkaido University, Sapporo, Japan.

McIntosh, R. A., Wellings, C. R., and Park, R. F. 1995. Wheat Rusts: An Atlas of Resistance Genes. Kluwer Academic Publishers, Boston, MA.

Millet, E. 2007. Exploitation of Aegilops species of section Sitopsis for wheat improvement. Isr. J. Plant Sci. 55:277-287.

Millet, E., Manisterski, J., Ben-Yehuda, P., Distelfeld, A., Deek, J., Wan, A., Chen, X., and Steffenson, B. J. 2014. Introgression of leaf rust and stripe rust resistance from Sharon goatgrass (Aegilops sharonensis Eig) into bread wheat (Triticum aestivum L.). Genome 57:309-316.

Milus, E. A., Lee, K. D., and Brown-Guedira, G. 2015. Characterization of stripe rust resistance in wheat lines with resistance gene $\mathrm{Yr} 17$ and implications for evaluating resistance and virulence. Phytopathology 105:1123-1130.

Njau, P. N., Jin, Y., Huerta-Espino, J., Keller, B., and Singh, R. P. 2010. Identification and evaluation of sources of resistance to stem rust race $\mathrm{Ug} 99$ in wheat. Plant Dis. 94:413-419.
Olivera, P. D., Kolmer, J. A., Anikster, Y., and Steffenson, B. J. 2007. Resistance of Sharon goatgrass (Aegilops sharonensis) to fungal diseases of wheat. Plant Dis. 91:942-950.

Pardey, P. G., Beddow, J. M., Kriticos, D. J., Hurley, T. M., Park, R. F., Duveiller, E., Sutherst, R. W., Burdon, J. J., and Hodson, D. 2013. Right-sizing stem-rust research. Science 340:147-148.

Patpour, M., Hovmøller, M., Justesen, A., Newcomb, M., Olivera, P., Jin, Y., Szabo, L. J., Hodson, D., Shahin, A. A., Wanyera, R., Habarurema, I., and Wobibi, S. 2016. Emergence of virulence to SrTmp in the Ug99 race group of wheat stem rust, Puccinia graminis f. sp. tritici, in Africa. Plant Dis. 100:522.

Pretorius, Z. A., Singh, R. P., Wagoire, W. W., and Payne, T. S. 2000. Detection of virulence to wheat stem rust resistance gene $\mathrm{Sr} 31$ in Puccinia graminis $\mathrm{f}$. $\mathrm{sp}$ tritici in Uganda. Plant Dis. 84:203.

Roelfs, A. P., and Bushnell, W. R. 1985. The Cereal Rusts. Volume II. Diseases, Distribution, Epidemiology and Control. Academic Press, Inc., Orlando, FL.

Roelfs, A. P., and Martens, J. W. 1988. An international system of nomenclature for Puccinia graminis f. sp. tritici. Phytopathology 78:526-533.

Roelfs, A. P., Singh, R. P., and Saari, E. E. 1992. Rust Diseases of Wheat: Concepts and Methods of Disease Management. CIMMYT, D. F., Mexico.

Schneider, A., Molnár, I., and Molnár-Láng, M. 2008. Utilisation of Aegilops (goatgrass) species to widen the genetic diversity of cultivated wheat. Euphytica $163: 1-19$

Scott, J. C., Manisterski, J., Sela, H., Ben-Yehuda, P., and Steffenson, B. J. 2014 Resistance of Aegilops species from Israel to widely virulent African and Israel races of the wheat stem rust pathogen. Plant Dis. 98:1309-1320.

Sheng, H., and Murray, T. D. 2013. Identifying new sources of resistance to eyespot of wheat in Aegilops longissima. Plant Dis. 97:346-353.

Sheng, H., See, D. R., and Murray, T. D. 2012. Mapping QTL for resistance to eyespot of wheat in Aegilops longissima. Theor. Appl. Genet. 125:355-366.

Sheng, H., See, D. R., and Murray, T. D. 2014. Mapping resistance genes for Oculimacula acuformis in Aegilops longissima. Theor. Appl. Genet. 127: 2085-2093

Singh, R. P., Hodson, D. P., Huerta-Espino, J., Jin, Y., Bhavani, S., Njau, P., Huerta-Foessel, S., Singh, P. K., Singh, S., and Govindan, V. 2011. The emergence of Ug99 races of the stem rust fungus is a threat to world wheat production. Annu. Rev. Phytopathol. 49:465-481.

Singh, R. P., Hodson, D. P., Jin, Y., Huerta-Espino, J., Kinyua, M. G., Wanyera, R., Njau, P., and Ward, R. W. 2006. Current status, likely migration and strategies to mitigate the threat to wheat production from race Ug99 (TTKS) of stem rust pathogen. CAB Rev. 1:1-13.

Singh, R. P., Hodson, D. P., Jin, Y., Lagudah, E. S., Ayliffe, M. A., Bhavani, S., Rouse, M. N., Pretorius, Z. A., Szabo, L. J., Huerta-Espino, J., Basnet, B. R., Lan, C., and Hovmøller, M. S. 2015. Emergence and spread of new races of wheat stem rust fungus: Continued threat to food security and prospects of genetic control. Phytopathology 105:872-884.

Stakman, E. C., Stewart, D. M., and Loegering, W. Q. 1962. Identification of physiological races of Puccinia graminis f. sp. tritici. USDA-Agricultural Research Service Publication No. E617.

Steuernagel, B., Periyannan, S. K., Hernández-Pinzón, I., Witek, K., Rouse, M. N., Yu, G., Hatta, A., Ayliffe, M., Bariana, H., Jones, J. D. G., Lagudah, E. S., and Wulff, B. H. 2016. Rapid cloning of disease-resistance genes in plants using mutagenesis and sequence capture. Nat. Biotechnol. 34:652-655.

USDA-ARS. 2015. Cereal Disease Laboratory. Resistance Genes. https://www ars.usda.gov/midwest-area/stpaul/cereal-disease-lab/docs/resistance-genes/resistancegenes/

USDA-ARS. 2016. Cereal Disease Laboratory. Small Grain Losses Due to Rust. https://www.ars.usda.gov/midwest-area/stpaul/cereal-disease-lab/docs/smallgrain-losses-due-to-rust/small-grain-losses-due-to-rust/

van Slageren, M. W. 1994. Wild wheats: A monograph of Aegilops L. and Amblyopyrum (Jaub. \& Spach) Eig (Poaceae). Wageningen Agric. Univ. Papers, Wageningen, Netherlands.

Vikas, V. K., Sivasamy, M., Kumar, J., Jayaprakash, P., KumarS., Parimalan, R., Kumar, A., Srinivasan, K., Radhamani, J., Jacob, S. R., Yadav, M., Rani, J., Bisht, I. S., Bhandari, D. C., Archak, S., Dutta, M., Tyagi, R. K., and Bansal, K. C. 2014. Stem and leaf rust resistance in wild relatives of wheat with D genome (Aegilops spp.). Genet. Resour. Crop Evol. 61:861-874.

Visser, B., Herselman, L., Park, R. F., Karaoglu, H., Bender, C. M., and Pretorius, Z. A. 2011. Characterization of two new Puccinia graminis f. sp. tritici races within the Ug99 lineage in South Africa. Euphytica 179:119-127.

Wan, A. M., and Chen, X. M. 2014. Virulence characterization of Puccinia striiformis f. sp. tritici using a new set of $Y r$ single-gene line differentials in the United States in 2010. Plant Dis. 98:1534-1542.

Wanyera, R., Kinyua, M. G., Jin, Y., and Singh, R. P. 2006. The spread of stem rust caused by Puccinia graminis f. sp. tritici, with virulence on $\mathrm{Sr} 31$ in wheat in Eastern Africa. Plant Dis. 90:113.

Whitcombe, J. R. 1983. A guide to the species of Aegilops L.: Their taxonomy, morphology, and distribution.International Board for Plant Genetic Resources (IPGRI), Rome.

Wulff, B. B. H., and Moscou, M. J. 2014. Strategies for transferring resistance into wheat: from wide crosses to GM cassettes. Front. Plant Sci. 5:692.

Yu, L.-X., Barbier, H., Rouse, M. N., Singh, S., Singh, R. P., Bhavani, S., HuertaEspino, J., and Sorrells, M. E. 2014. A consensus map for Ug99 stem rust resistance loci in wheat. Theor. Appl. Genet. 127:1561-1581. 